\title{
Melatonin: A Powerful Integrative Adjunctive Agent for Oncology
}

\author{
Robert Schettig, Trevor Sears, Matthew Klein, Ruth Tan-Lim, Ronald Matthias, \\ Christopher Aussems, Michael Hummel, Rory Sears, Zachary Poteet, Daniel Warren, \\ John Oertle, Connor Coffin, Dino Prato*
}

Envita Medical Center, Scottsdale, AZ, USA

Email: ${ }^{\star D i n o P r a t o @ g m a i l . c o m ~}$

How to cite this paper: Schettig, R., Sears, T., Klein, M., Tan-Lim, R., Matthias, R., Aussems, C., Hummel, M., Sears, R., Poteet, Z., Warren, D., Oertle, J., Coffin, C. and Prato, D. (2020) Melatonin: A Powerful Integrative Adjunctive Agent for Oncology. Journal of Cancer Therapy, 11, 571-596. https://doi.org/10.4236/jct.2020.119049

Received: August 23, 2020

Accepted: September 25, 2020

Published: September 28, 2020

Copyright ( 2020 by author(s) and Scientific Research Publishing Inc. This work is licensed under the Creative Commons Attribution International License (CC BY 4.0).

http://creativecommons.org/licenses/by/4.0/ (c) (i) Open Access

\begin{abstract}
Melatonin is an established hormone supplement and has been well recognized for its effect on the circadian cycle to improve sleep, REM (rapid eye movement), and aiding in jetlag recovery. The utility of melatonin extends beyond sleep aid, however. This hormone also possesses less well-known antioxidant action and even robust anticancer activity. Melatonin may be a key supplement for addressing age-related neurologic decline while serving as a valuable adjunctive cancer treatment that reduces drug resistance in tumors and downregulates angiogenesis. In immunotherapy, melatonin activates Natural Killer (NK) cells nested within tumoral tissue and does not have the side effect profile of other immunoreactive agents used for chemotherapy. Since melatonin is found in high concentrations in the brain and other hormone-linked tissues, the relevance of melatonin is increased for the treatment of estrogen-linked cancers. The immunomodulatory effect of melatonin may also help with chronic inflammation seen in patients with autoimmune disorders. All of these effects together represent a unique and versatile therapeutic agent for integrative medicine. No other commercially available drug possesses all of these therapeutic mechanisms while having a very minimal side effect profile and being considered overall to be safe to use. Currently, melatonin is underutilized in medicine, especially in the field of integrative oncology and represents a crucial supportive adjuvant to improve the lives of patients.
\end{abstract}

\section{Keywords}

Melatonin, Oncology, Immunotherapy, Chronic Inflammation, Autoimmune, Envita, Antioxidant, Anticancer, Antiangiogenesis, Telomerase, Metastasis, Anti-Proliferation, Pro-Apoptosis, Immune System Activation, Cancer Adjuvant, Chemotherapy Synergy 


\section{Introduction}

Melatonin (N-acetyl-5-methoxytrytamine) is a hormone produced primarily by the pineal gland and also by nearly every tissue in the body. Originally, melatonin was believed to be produced exclusively in the pineal gland, but it has been determined that melatonin is also produced in the mitochondria and thus by almost every cell in the body [1] [2] [3]. Melatonin is mainly responsible for regulating the sleep-wake cycle in humans but has other utilities, as we will discuss in this report [4]. There is ten to fifteen times the amount of melatonin in the blood at night as during the day, and release from the pineal gland is strongly influenced by exposure to light sources such as the sun but also electronic devices [5]. Individuals commonly supplement orally with it for difficulty sleeping, especially from working nights or jet lag [6] [7] [8]. Melatonin has been observed to be effective at treating symptoms of non-depression-related insomnia resulting from shift work and jet lag but is not FDA approved for these uses [9]. Melatonin has been investigated for health benefits beyond use as a natural sleep aid (Figure 1).

There is good reason to believe that melatonin could be useful as more than a remedy for mild insomnia. Research in-vivo and in-vitro has shown multiple biological functions for this neurohormone including, but not limited to, assisting in the immune response, reducing oxidative stress, helping eye function, regulating many internal cellular processes, and even protecting cells from ionizing radiation [5] [10] [11]. To start with, the quantity of melatonin fluctuates in the human body throughout the day as part of the circadian rhythm. In addition to the pineal gland, melatonin is produced by several other organs inside the body, in particular, the stomach [12]. Production of melatonin is strongly influenced by light exposure and the circadian rhythm. Exposure to the blue end of the visible



Figure 1. Melatonin molecular structure. 
light spectrum has been shown to decrease melatonin drastically [13], but the absence of light does not by itself stimulate the production of this neurohormone; it only permits serum levels to rise [14]. Interestingly, melatonin levels also generally decrease with age, potentially explaining the marked reduction in sleep hours associated with old age [15].

Melatonin has been linked with potential oncostatic properties on tumors of different type and stage through epidemiological studies [16]. Also, experimental in-vitro and animal models have shown possible growth inhibition of some human tumor cells by melatonin [16]. Antioxidant activity, stimulation of apoptosis, regulation of pro-survival signaling and tumor metabolism, modulation of melatonin receptors MT1 and MT2, inhibition on angiogenesis, metastasis, and induction of epigenetic alteration have been considered as options for the underlying mechanisms of melatonin's anti-tumor activity. In addition to potential tumor growth inhibition, melatonin may also be beneficial as a cancer therapy adjunct by reducing the side effects and supporting the therapeutic effect of chemotherapy or radiation [16]. Melatonin has been correlated with the treatment of many types of cancer, such as lung cancer, prostate cancer, breast cancer, gastric cancer, and colorectal cancer [16]-[21].

Melatonin interacts with two primary receptors, MT1 and MT2 [22]. These receptors are associated with different stages of sleep. MT1 controls deep sleep and REM sleep, while MT2 controls the stage of sleep immediately preceding the dream cycle [22]. MT1/MT2 receptors are present in a variety of organs and immune cells inside the body, leading some researchers to speculate about the function of melatonin in controlling aspects of the host immune response and other functions throughout the body [23].

MT1 and MT2 are G protein-coupled receptors and are linked intrinsically to the endogenous oscillatory action of pineal melatonin, which occurs inside the suprachiasmatic nucleus $(\mathrm{SCN})$ in response to daily light exposure. The light-dark cycle of each day, as well as seasonal changes, trains circadian oscillators inside the SCN, which contains a large number of MT1 and MT2 receptors and may serve as a feedback mechanism of the circadian rhythm [24]. MT1/MT2 receptors have many functions in the brain which are still being investigated. For example, MT1/MT2 can form heterodimers with serotonin receptor $5-\mathrm{HT}_{2 \mathrm{C}}$ [25]. This mechanism is of importance in understanding the antidepressant mechanism behind drugs like agomelatine, which is both a melatonin receptor agonist and a 5- $\mathrm{HT}_{2 \mathrm{C}}$ receptor antagonist [25] [26]. A full understanding of the function of receptors like MT1/MT2, 5- $\mathrm{HT}_{2 \mathrm{C}}$, and others could unlock more therapeutic potential and lead to the development of new melatonin-like drugs.

The field of research into melatonin receptors is ongoing. For example, the X-ray free electron laser (XFEL) structures of MT1 and MT2 were just described in 2019 [27] [28]. Detailing the molecular structure of the receptors reveals interesting facts such as differences between MT1 and 5-HT receptors which have similar ligands and which both respond to agomelatine. The binding site of MT1 
is very compact and is only accessible through a narrow channel allowing for only atypical ligand entry into MT1 [27]. MT2 function has been implicated in type 2 diabetes and other disorders such as mood disruptions and the development of cancer in addition to insomnia [28]. Studying the MT2 receptor's structure reveals the potential for an extra cellular ligand entry point in addition to the intramembrane entry point common to both melatonin receptors [28]. This is important for understanding the selectivity of the two receptors and potentially for designing better drugs in the future which impact melatonin receptors.

In the United States, major depressive disorder is the most prevalent mental disorder and is a significant cause of disability; it impacts approximately 100 million adults in the world [29]. Major depressive disorder is characterized by anxiety, neurochemical imbalances, disturbances in sleep pattern, circadian/seasonal rhythm entrainment, low vitamin $\mathrm{D}$, lack of motivation/mood, and an increased rate of neuronal atrophy [29] [30]. Current treatment options include tricyclic antidepressants and selective serotonin reuptake inhibitors, but neither of these types of drugs treats sleep disturbances, and each can lead to undesirable side effects through long-term use [31] [32]. These side effects include sexual dysfunction, weight gain, and several other cognitive and motor manifestations which form the Serotonin Syndrome. MT1/MT2 are thus important targets for novel antidepressants.

There is some evidence to believe that melatonin or melatonin-like drugs which target melatonin receptors may be of use as a clinical antidepressant. The drug Luzindole blocks melatonin-mediated antidepressant effects in the forced swim test, suggesting that MT1/MT2 is involved in its function [33] [34]. Ongoing melatonin treatment has also been shown to positively affect neurogenesis in rats, a process believed to be essential for the effectiveness of antidepressants. Additionally, irregular melatonin levels correlate to the development of both cardiovascular disease and cancer [35]. These and other data that we will outline in the sections below imply a wide range of potential therapeutic benefits for melatonin, which would benefit from further published data and clinical trials.

\section{Melatonin and Inflammation}

It was mentioned previously that a wide variety of cells contain melatonin receptors, and this includes several classes of immune cells [23]. Melatonin is an immunomodulatory hormone, which is to say that it reduces excessive immune activity in conditions of chronic inflammation and increases immune function in immune-suppressed individuals. For example, melatonin reduces the production of inflammatory cytokines (IL-6, IL-8, and TNF- $\alpha$ ) [36]. Melatonin also appears to reduce inflammation in the brain by reducing ROS/RNS in microglia, specialized immune cells specific to the central nervous system [37]. Melatonin is essential for maintaining a healthy immune response and has been observed to reverse immune suppression caused by factors including steroid and chemical exposure or old age [23]. 
Melatonin stimulates both the innate and adaptive immune responses, according to multiple studies [23] [38] [39]. Melatonin may also contribute to an enhanced T-cell mediated immune response. This effect is produced by thymosin- $\alpha$, thymulin, and other thymus-derived peptides, which melatonin enhances [40]. CD $4^{+}$T-lymphocytes and monocytes may benefit from melatonin as well as a protective effect [41] [42]. A consensus drawn from several studies demonstrates that melatonin administration can be beneficial for patients with infectious diseases with melatonin-administered patients having shortened disease duration and improved clinical outcomes [23] [43].

\section{Evidence for Anticancer Properties of Melatonin}

Perhaps the most important use for melatonin supplementation is as an adjuvant for cancer treatment. There is much evidence that melatonin helps enhance the therapeutic effects of chemotherapy/radiation while reducing its side effects, as we will outline in this section. Researchers consider melatonin to be an excellent candidate for study and consider it to have the potential for the prevention and treatment of multiple kinds of cancer, including breast, prostate, gastric, and colorectal [16].

Various types of cancer are responsive to melatonin treatment in-vitro and in-vivo at daily doses of 10 - $50 \mathrm{mg}$. Among these include breast cancer [44] [45], metastatic renal carcinoma [46], non-small-cell lung cancer [47], hepatocellular carcinoma [48], and brain metastases [49]. As an example, a study of fourteen patients with tamoxifen-resistant, metastatic breast cancer demonstrated that $20 \mathrm{mg}$ of melatonin could have a positive effect. In 28 percent of those patients, a partial response was seen where the disease was expected to progress rapidly, and in those who responded significantly lower serum levels of tumor growth factor IGF-1 were recorded ( $p<0.001$ ). The tumor factor response was independent of estrogen-receptor status [45].

Of particular interest is the response to non-small-cell lung cancer (NSC), which is a type of cancer known for being unresponsive to conventional therapy. A randomized trial with 63 NSC patients, all in Stage 4, had patients who had already failed initial treatment with cisplatin placed on either melatonin or supportive care alone. Mean survival time was significantly greater in the melatonin group at 7.9 months compared to 4.1 months $(\mathrm{p}<0.05)$ [47].

For patients whose cancer spreads to the brain, there are often few treatment options available, and survival time is frequently less than six months. A different randomized study included fifty cancer patients with recorded brain metastases and who had all already received initial therapy. They were separated into two groups for either supportive care alone or supportive care with melatonin. The observed metrics (1-year survival, mean survival time, and time free from brain tumor progression) were all significantly higher in the melatonin group than the control group [49].

Much of the anticancer impact from melatonin appears to stem from its anti- 
angiogenic property; antiangiogenic drugs are sometimes administered alongside chemotherapy to enhance the effect of the treatment. González et al. studied the impact of melatonin when used alongside chemotherapy drugs, docetaxel, and vinorelbine. They found that the drugs' inhibition of the processes involved in angiogenesis (cell proliferation, migratory capacity, and vessel formation) were all intensified by melatonin [50]. Specific to estrogen biosynthesis, melatonin also reduced the negative impact of vinorelbine by inhibiting the expression and activity of aromatase and sulfatase [50]. This indicates that estrogens are crucial in the tumorigenesis and progression process for at least some forms of cancer. For this review, we will refer primarily to estrogen receptor alpha, which is overexpressed in these types of cancers. After over 100 years of research into the area of breast cancer, there is considerable evidence pointing towards estrogens as a principle mammary carcinogen [51].

Cohen et al. proposed in 1978 that diminished pineal gland function (the gland which produces melatonin) may lead to an increased incidence of breast cancer through the mechanism of sustained quantities of elevated estrogens. The hypothesis was based on several observations [52]:

1) The incidence of breast cancer is low in areas where pineal gland calcification is also low.

2) Patients who take chlorpromazine (a sedative which increases melatonin) have lower rates of breast cancer.

3) In vitro research demonstrated a direct effect of melatonin against breast cancer cells.

4) Melatonin receptors are present in high quantities on human ovarian cells, suggesting that melatonin might have a direct impact on estrogen production in the ovaries.

Cohen et al. made these propositions over 40 years ago as of the time of this writing, and evidence has only increased for the relevance of melatonin in modern cancer treatment. For example, in animal studies, enhanced pineal gland function or exogenous melatonin supplementation $(500 \mathrm{mg} / \mathrm{day}$ two weeks before challenge by DMBA) decreased the number of tumors and tumor size in the rodents [53]. The same study also showed higher tumor regression in the induced tumors in the animals which received melatonin.

The potential anticancer mechanism of melatonin has been given a great deal of scrutiny by investigators, especially in hormone-dependent cancers. Breast cancer is often hormone-dependent and is one of the most common cancers among women. According to the American Cancer Society, over $70 \%$ of initial-stage breast cancer cases are hormone-dependent [54]. The chemo-sensitization effect of melatonin is also of interest. Pariente et al. described melatonin enhancing the effect of 5-fluorouacil in patients with colorectal adenocarcinoma [55].

Zinc-dependent matrix metalloproteinases (MMP's) are a group of enzymes associated with remodeling of the extracellular matrix and are essential for many normal and disease states inside the body; these processes range from embryonic 
development and bone remolding to cancer, arthritis, and neurological disease [56]. Adenocarcinoma is one of these diseases reliant on MMP (or matrixin) function due to its dysfunctional extracellular matrix (ECM) turnover [57]. MMP-9 is an important matrixin which is often released by inflammatory cells such as neutrophils, monocytes, macrophages, and mast cells [58] [59]. It is required for bone regrowth [60], angiogenic revascularization of oxygen-starved tissues [61], and remyelination [62], but has also appeared in many pathological processes. MMP-9 is involved with inflammation, infection, progressive neurological disease, cardiovascular disease, and several autoimmune disorders [63] [64] [65] [66] [67]. Specifically, concerning cancer, MMP-9 may serve a function in the processes of cancer cell invasion, metastasis, and tumor progression [68] [69]. Specifically, concerning cancer, MMP-9 may serve a function in the processes of cancer cell invasion, metastasis, and tumor progression [68] [69]. MMP-9 facilitates the release of vascular epidermal growth factor, which activates the angiogenic switch [70]. In different forms of neoplasms, such as colon and breast tumors, internal measurements of MMP-9 have been found to be elevated compared to normal values [71] [72]. Due to these observations, inhibition of MMP-9 activity has since become a target for therapeutic research. Unfortunately, the development of broad-spectrum MMP inhibitors has so far produced disappointing results, among the chief problems being lack of specificity and toxic side effects to host physiological systems. While some progress has been made with phosphinic acid and carboxylate inhibitors [73], for this review, we wish to concentrate our attention on melatonin as an MMP inhibitor.

Melatonin downregulates MMP-9 when used to prevent induced gastric ulcers and alcohol-related liver injury in rodents [74] [75]. An antitumoral action for melatonin has also been described concerning suppressing the emergence of colon cancer in cases of chronic Irritable Bowel Disease (IBD) [76]. The antioxidant action of melatonin, as previously discussed, may also contribute to its protective effects [33] [77] [78] [79]. Rudra et al. describe how melatonin inhibits MMP-9 activity in a dose-dependent manner [80]. In describing the thermodynamics of the interaction between melatonin and MMP-9, Rudra, et al. claimed that the melatonin binding site on MMP-9 is highly favorable [80]. The conclusions that these researchers were able to draw was that melatonin had a direct suppressive effect on MMP-9 in-vitro and that melatonin also suppressed MMP-9 in gastric adenocarcinoma cells taken from humans [80]. Melatonin binds to the catalytic domain of MMP-9, thus inhibiting its function. Because MMP-9 is implicated in both inflammatory disease and disease processes of cancer, such as tissue invasion and angiogenesis, it may be a therapeutic target for several kinds of cancer. As an MMP-9 inhibitor, melatonin is a natural compound with a high amount of potential as a therapeutic agent to slow or reverse the impact of certain kinds of cancer relying on MMP-9 function.

The regulatory nature of melatonin and its connection to the body's biological clock, research has concentrated on melatonin for its relation to aging and 
age-related disease, including the gradual decline of immune function and the development of neoplastic diseases. For many different kinds of tumors, melatonin has been observed to inhibit growth both in-vitro and in-vivo [81]. Extrapolating from this research, physicians are interested in the use of melatonin as a potential adjunctive agent for chemotherapy/radiotherapy either by itself or alongside interleukin-2. For patients with advanced solid tumors, administration of melatonin in this manner has been associated with improved outcomes and survival [81]. Just as importantly, the administration of melatonin has also been shown to assist patients with tolerating chemotherapy and reducing its potentially devastating side effects [81].

In addition to observing the effect of melatonin on matrix metalloproteases, there is also considerable evidence that melatonin is an immune modulator. There is a measurable increase in the number of circulating hemopoietic stem cells, progenitor cells, and mature leukocytes at night, the time of day when melatonin is naturally higher [82]. During the day, typically levels of cortisol, adrenaline, noradrenaline, TNF- $\alpha$, and interleukin-1- $\beta$ are elevated compared to nighttime levels [82]. This circadian rhythm is fundamental in humans, and regular disruption in the sleep/wake cycle has been associated with an increased risk for cardiovascular disease and the development of neoplasms [83] [84]. Blask et al. studied women who worked night shifts and are thus exposed to light at night and found that this group had a significantly higher risk of developing breast cancer [85].

There is more than epidemiological evidence suggesting that melatonin is important for the prevention of cancer. When melatonin was administered to patients for 7 - 14 days, an increase in natural killer (NK) cells and monocytes was observed in the bone marrow as well as increased hemopoiesis [23] [38]. These monocytes are also known to contain melatonin receptors both on their outer membranes and within the nucleaus [38]. In these immune cells (monocytes and macrophages), melatonin appears to stimulate the production of inflammatory cytokines (IL-1, IL-6, IL-12, and TNF- $\alpha$ ) while reducing IL-10. Melatonin stimulates ROS production within macrophages, an action which potentiates their phagocytic ability [38] [86]. This effect on NK-cells is critical because NK-cells play a significant role in the body's immune surveillance against early cancer formation and viral infections [87]. Even short-term supplementation of melatonin has been seen to increase interferon- $\gamma$ production from NK-cells, and long-term supplementation of melatonin increased the quantity and activity of NK-cells in serum [38].

In addition to NK-cells, melatonin also appears to impact regulatory T-cells. Regulatory T-cells have an inhibitory effect on anticancer immune activity, with some tumors recruiting regulatory T-cells to block the immune system. Melatonin inhibits the activity of regulatory T-cells [88]. Liu et al. showed that melatonin led to significant downregulation of regulatory T-cells present inside tumors along with Foxp3 gene expression, leading to an overall reduction in tumor size 
[89]. While this was in an animal study, decreasing regulatory T-cells have also been demonstrated in cancer patients given melatonin [90].

Both of NK-cells and regulatory T-cells are related to inflammation in the tumor microenvironment. These and other immune cells, as well as activated fibroblasts, infiltrate the tumor and secrete a variety of complex signaling agents, including cytokines, chemokines, and growth factors. The tumor and the host immune system both react to these secreted signaling compounds [91]. Marotta et al. has shown that inflammation signaling through agents such as IL-6, JAK2, and Stat 3 plays a critical role in the stem cell-like capabilities of breast cancer cells [92]. Tracking changes in cytokine levels in serum is already well established in clinical practice. For example, IL-6 is known to potentially stimulate cancer growth, contributing to tumor recurrence and metastasis in breast cancer patients [93].

Melatonin signaling appears to be prevalent in T-cells, which contain both membrane (MT1/MT2) binding sites and nuclear binding sites [94] [95] [96] [97]. Membrane receptors MT1 and MT2 have already been mentioned, and the nuclear receptors include orphan receptor retinoid $\mathrm{Z}$ (the first to be identified) and retinoic acid-related orphan receptor alpha [98] [99]. In 1995, human CD4 $4^{+}$ cells were confirmed to have high-affinity binding sites for melatonin, while rat thymus gland cells have been described to possess melatonin receptors, including $\mathrm{CD}^{+}, \mathrm{CD}^{+}, \mathrm{CD}^{+} \mathrm{CD}^{+}$, and $\mathrm{CD}^{-} \mathrm{CD}^{-}$[100] [101]. There are also receptor-independent interactions between melatonin and T-cells. Melatonin has been described to enhance T-cell survival through inhibition of calcineurin, which is a nuclear factor of activated T-cells [42]. It is through these T-cell mediated mechanisms that melatonin exerts beneficial effects on a variety of inflammatory conditions, including diabetes, multiple sclerosis, and systemic lupus erythematosus [102]. In the case of multiple sclerosis, $\mathrm{T}_{\mathrm{H}} 17$ helper T-cells may also be relevant. These cells are associated with disease flares in patients with multiple sclerosis, and melatonin has been shown to interfere with the polarization and effector functions of $\mathrm{T}_{\mathrm{H}} 17$ helper T-cells, lowering their population in serum [103]. In addition to multiple sclerosis, $\mathrm{T}_{\mathrm{H}} 17$ cells may be relevant for broader autoimmunity conditions and cancer [104]. $\mathrm{T}_{\mathrm{H}} 17$ is in several ways opposed to regulatory T-cells, which have functions related to self-tolerance and defense against autoimmune disorders, processes that are also relevant to intermediary and late stages of cancer [104]. Regulatory T-cells secrete inhibitory cytokines such as IL-10 and TGF- $\beta$ as part of their mechanism of action. They are also capable of engaging inhibitory checkpoint molecules TIGT and CTLA. Like two ends of a scale, TH17 promotes autoimmunity, carcinogenesis, and antitumor immunity, while regulatory $\mathrm{T}$-cells are required for self-tolerance and tend to dampen autoimmunity and antitumor immunity [104]. This is further supported by evidence from Kawaguchi et al. which describe the connection between inflammatory cytokines like IL-10 and TGF- $\beta$ and the progression of tumors as observed in breast cancer patients [91]. 
In mice that have undergone pinealectomy, the expressions of $T_{H} 1, T_{H} 2$, and $\mathrm{T}_{\mathrm{H}}$ 17-related cytokines are all reduced [23]. As mentioned previously, the pineal gland is the principal source of melatonin in the body. In the pinealectomized mice, melatonin supplementation rapidly increased cytokine levels, leading to a gradual recovery of normal cytokine expression levels [104]. Following the procedure, activation of $\mathrm{T}$ and $\mathrm{B}$-cells fell significantly with a reduction in the population of both types of cells, and downstream factors of these cells (TLR3, P38, JNK, and NFK-B) were down-regulated by melatonin supplementation even compared to levels seen in the control group. These results led Luo et al. to conclude that melatonin is actively involved in immune regulation in mice and other vertebrates [105].

Many in-vitro studies have reported an oncostatic effect for melatonin in multiple strains of cancer cells, including mammary-ovarian, prostate, melanoma, hepatocarcinoma, and colorectal cancer. The general conclusion from these experiments is that melatonin inhibits cell proliferation and induces apoptosis in most tumor cell lines [106]. Other studies suggest that melatonin may synergize well with newer cancer treatments that utilize checkpoint inhibitors [15] [106] [107]. The observed oncostatic effect is mediated through several different effects which are listed below:

- Antioxidant

- Melatonin detoxifies multiple free radicals, including the hydroxyl radical and reactive nitrogen species [108].

- Melatonin recharges other antioxidant enzymes like glutathione and superoxide dismutase [106] [108].

- Reducing ROS cell damage is relevant in all three steps of carcinogenesis (initiation, progression, and metastasis) [106] [108].

- Estrogen Receptor Expression

- Melatonin decreases the expression of estrogen-receptor- $\alpha$ [106].

- Modulation of the Cell Cycle and Cell Differentiation

- Melatonin increases the duration of the cell cycle in multiple cancer lines by expanding the G1 phase and delaying entrance into the $S$ phase. This effect is mediated through the upregulation of tumor suppressor gene p53 and kinase inhibitor p21 [106].

- Telomerase and Metastasis inhibition

- Melatonin decreases telomerase activity in most cancer cells. Lower invasiveness is also observed with an increase in microfilaments and adhesion plaques [109].

- Antiangiogenesis

- Antiangiogenesis is observed with melatonin likely through an inhibitory action on tumor growth factors that stimulate angiogenesis (IGF, EGF, VEGF, and ET-1) [89].

- Immune System Activation

- Melatonin stimulates the production of monocytes, NK-cells, and other 
immune cells while downregulating regulatory T-cells [88].

- Synergy with Chemotherapy

- Melatonin increases the sensitivity of cancer cells to certain chemotherapy agents [108]. There is also a synergistic effect with other antineoplastic drugs through the promotion of the apoptotic pathway [107].

- Anti-proliferation and Pro-apoptosis regulation

- Melatonin has been observed to decrease cell proliferation while increasing apoptosis, including in apoptosis-resistant cell lines like hepatocarcinoma [110] (Figure 2).

\section{Importance of Melatonin in the Brain}

As mentioned previously, melatonin possesses antioxidant activity, which is relevant to controlling inflammation both as an end to itself and as a means of controlling other conditions associated with chronic inflammation, including tumorigenesis [111] [112] [113]. Melatonin increases several antioxidant enzymes, including superoxide dismutase, glutathione peroxidase, and $\gamma$-glutamyl cysteine synthetase [11] [15] [114]. Each of these enzymes can increase or recharge other antioxidants like glutathione. It is essential to maintain healthy levels of these enzymes because they are vital to the optimal function of mitochondria, where a lot of reactive oxygen species (ROS) are created as a byproduct of aerobic respiration [115]. Failure to maintain adequate levels of antioxidants and their supporting enzymes results in oxidative stress, which can damage the cell and the body's tissues and both cause and accelerate a variety of chronic diseases and potentially accelerate the complications of aging itself. In addition to helping increase the levels of these enzymes, however, melatonin can also bind directly to ROS and Reactive Nitrogen Species (RNS), neutralizing the

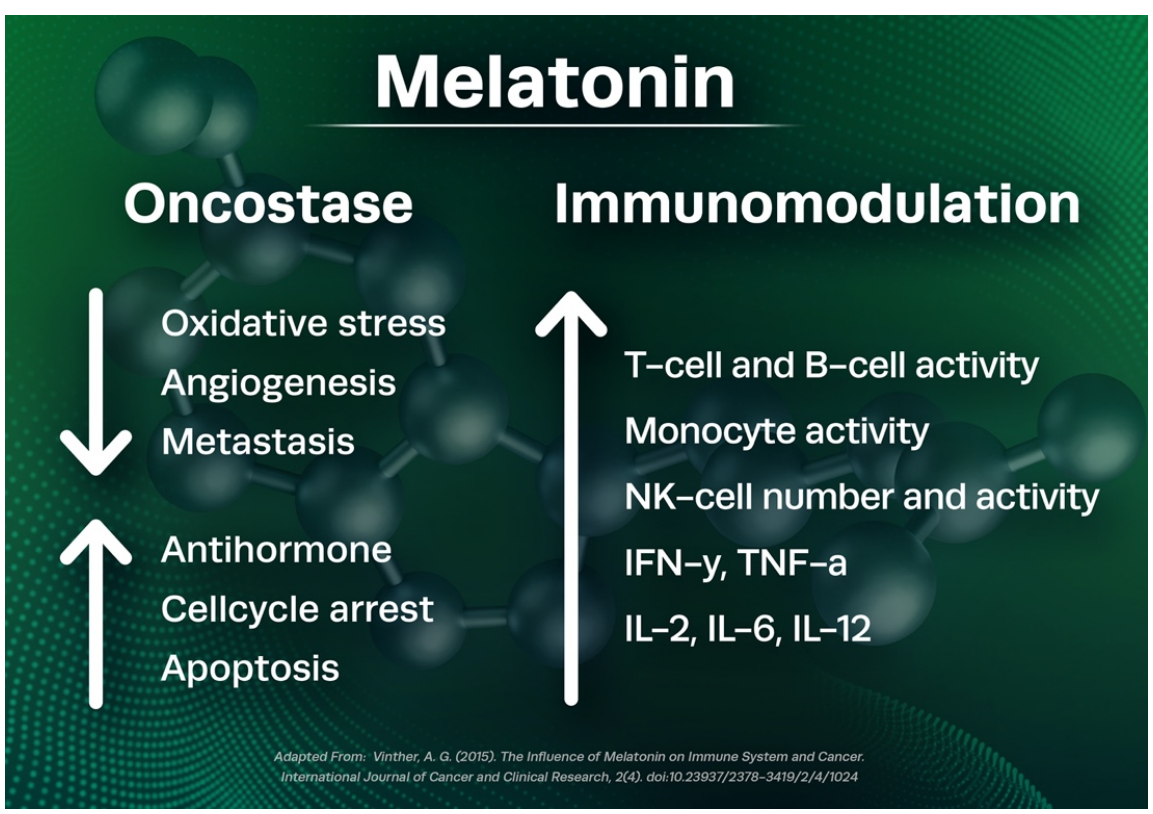

Figure 2. Summary of melatonin anticancer properties. 
oxidative threat [15]. This mechanism allows melatonin to both directly and indirectly protect tissues and organ systems from oxidative damage. The most important tissues that produce melatonin and rely on its protection from ROS/RNS (oxidative damage) include the gut, ovaries, testicles, bone marrow, eye lenses, and the brain [36]. Most of the metabolites of melatonin are also ROS/RNS scavengers as well, which means that melatonin provides significant oxidative protection even after the first stages of metabolism [15]. Just one molecule of melatonin can neutralize up to 10 ROS/RNS molecules based on the chemistry of the hormone and its resulting products [116]. Melatonin also blocks the activity of nitric oxide synthase, which is an enzyme that produces RNS and promotes inflammation [117].

When considering brain health and the importance of antioxidants, most ROS/RNS are generated in the cell. Mitochondria are the power stations of the cell where most of the energy needed for ATP production and survival is produced [118]. Inside the cell, the mitochondria and the nucleus are the areas that contain the most melatonin, [119] considering that mitochondria produce most of the ROS/RNS in the body. Even though the mitochondria are the source of ROS and RNS, the proteins and structures of mitochondria can be damaged by ROS/RNS, making oxidative control systems extremely important in managing this dangerous waste product of aerobic respiration. Damage from ROS/RNS can damage proteins and create holes in lipid membranes, and if mitochondria begin to leak from holes in their membranes, this can lead to cell death [15].

In examining the function of toxins, several that disrupt mitochondrial function also lead to symptoms of neurodegenerative disease. Laboratory animals that have been poisoned by these compounds are often used to study neurodegenerative diseases. A few of these compounds and their effects are outlined in the table below.

Brain tissue is very vulnerable to free radical damage owing to the large amount of oxygen consumption necessary to brain function (about $20 \%$ of total oxygen intake) as well as high concentrations of polyunsaturated fatty acids [126], and transition metals that can participate in the creation of hydroxyl radicals [127]. In the brain, the primary antioxidant is Glutathione (GSH), which is present in the millimolar range [128]. However, melatonin is ubiquitous in the brain tissue and is also an important free radical scavenger with indirect antioxidant activity [79] [129]. This is relevant to many neurodegenerative diseases because existing evidence points towards an accumulation of aberrant, misfolded proteins, protofibril formation, oxidative and nitrosative stress, ubiquitin proteasome dysfunction, mitochondrial injury, and failures in the axonal/dendritic transport systems as all being unifying factors in the origin and progression of these diseases [130]. These factors can lead to accelerated cognitive decline and contribute to complications in chronic diseases that impact the central nervous system. In Table 1, three compounds are listed which produce effects similar to neurological disease. In each case, melatonin had a therapeutic effect in reducing signs of neurological damage. 
Table 1. Compounds and their effects.

\begin{tabular}{|c|c|}
\hline Rotenone & Produces symptoms similar to Parkinson's disease in rats [120]. \\
\hline MPTP (1-methyl-4 phenyl-1,2,3,6-tetrahydropyridine) & $\begin{array}{c}\text { Produces symptoms similar to Parkinson's disease [121]. In mice, an injection of } \\
\text { melatonin prevents much of the damage to fats and DNA in several parts of the } \\
\text { brain after MPTP poisoning [122]. This may be the result of reconfiguring proteins } \\
\text { to their normal state after MPTP exposure }\end{array}$ \\
\hline 3-NPA (3-nitropropionic acid) & $\begin{array}{l}\text { Derived from a fungus that infects sugarcane, there have been recorded incidents } \\
\text { of children eating the fungal-contaminated sugarcane and afterward developing } \\
\text { a condition similar to Huntington's disease [123]. In rats dosed with 3-NPA, } \\
\text { melatonin was observed to prevent nerve cell loss, correct damaging behavior, } \\
\text { prevent protein damage, and restore dopamine levels to their normal range [123]. }\end{array}$ \\
\hline Cyanide & $\begin{array}{l}\text { Cyanide is a very lethal poison that causes mass-death of nerve cells and seizures, which } \\
\text { can easily lead to death [124] [125]. It also damages mitochondria inside of nerve cells. } \\
\text { In mice, a prior dose of melatonin reduced the severity of seizures caused by a cyanide } \\
\text { injection [125]. As well, in-vivo and in-vitro tests showed that mitochondrial DNA } \\
\text { damage from potassium cyanide was lessened by melatonin [124]. }\end{array}$ \\
\hline
\end{tabular}

\section{Safety Data and Side Effects}

Melatonin is generally considered safe to use even by conventional institutions such as the Mayo Clinic and the National Center for Complementary and Integrative Health [131] [132]. This definition applies to small doses of melatonin usually taken for short-term relief from insomnia and other sleep disturbances. NIH still considers other uses of melatonin to be as yet unproven and to be utilized with caution and under the supervision of a healthcare professional until clinical drug trials are conducted.

NIH mentions the following risk factors when taking melatonin [131]:

- Interactions with medication

- With all supplements, a healthcare provider should be consulted for possible interactions with other medications. In particular, patients with epilepsy or who are taking blood thinners should be under medical supervision while taking melatonin supplements.

- Possible allergic reactions

- There is always a potential for an allergic reaction when taking any supplement.

- Safety for pregnant and breastfeeding women

- There has not yet been sufficient research into the impact of melatonin on pregnant women or women who are breastfeeding.

- Concerns for the elderly

- The 2015 guidelines released by the American Academy of Sleep Medicine recommended against the use of melatonin by people with dementia [131].

- Melatonin may remain active in the bodies of older people for a longer time, resulting in daytime drowsiness.

There are several side effects of melatonin use as noted by both NIH and the Mayo Clinic [131] [132] [133] [134]: 
- Headache

- Dizziness

- Nausea

- Sleepiness

- Rebound insomnia

- Heart palpitations

- Abdominal pain

- Potential hepatotoxicity

Because of the slight hepatotoxicity, liver failure, renal failure, alcohol addiction, and high lipid levels should be considered as contraindications when prescribing melatonin [135]

Rarely reported side effects of melatonin include the following [134]:

- Nasopharyngitis

- Arthralgia

- Tachycardia

- Vomiting

- Nightmares

- Difficulty swallowing and breathing

- Hypnotic activity

- A feeling of heaviness in the head

- Heartburn

- Belching

- Swelling in the arms or legs

- Sweating

- Hot flashes

- Exanthema

- Sleep problems

- Depression

- Sleepwalking

Intravenous administration of melatonin has been described to increase peripheral blood circulation, leading to potentially undesirable side effects. These include vasoconstriction in cerebral arteries and a decrease in body temperature owing to increased blood flow to distal parts of the body [136]. The immune stimulatory effect of melatonin may also be undesired in patients with autoimmune disorders, and melatonin or melatonergic drugs may be contraindicated in these cases [137]. In some animal studies, melatonin has been described as carcinogenic in very high doses [133]. As with any agent, correct dosing is important (Table 2).

\section{Conclusions}

Melatonin was identified early on as a key component of the body's organic clock and circadian rhythm, but since then, it has become clear that this natural compound has other potential therapeutic uses as well. Melatonin is an indirect 
Table 2. Melatonin dosage options.

\begin{tabular}{|c|c|c|c|c|}
\hline \multicolumn{5}{|c|}{ Melatonin Dosage for Cancer Care } \\
\hline Oral & Starting Dosage & 20 mg daily & Max Dosage & $\begin{array}{l}100 \mathrm{mg} \text { daily } \\
\text { (Toxic dosage has never been reached) }\end{array}$ \\
\hline Intravenous & Starting Dosage & $10 \mathrm{mg}$ daily & Max Dosage & $\begin{array}{c}50 \mathrm{mg} \text { daily } \\
\text { (titrate by } 10 \mathrm{mg} \text { until max dose is reached) }\end{array}$ \\
\hline Topical & Starting Dosage & $\mathrm{X}$ & Max Dosage & $\mathrm{X}$ \\
\hline \multicolumn{5}{|c|}{ Melatonin Dosage for Sleep Issues } \\
\hline Oral & Starting Dosage & $1 \mathrm{mg}$ daily & Max Dosage & $5 \mathrm{mg}$ daily for sleep \\
\hline $\begin{array}{l}\text { Intravenous-IV melatonin for } \\
\text { sleep is only appropriate if unable } \\
\text { to absorb or administer orally }\end{array}$ & Starting Dosage & $10 \mathrm{mg}$ daily & Max Dosage & $10 \mathrm{mg}$ daily. \\
\hline Topical & Starting Dosage & $2.5 \mathrm{mg}$ daily & Max Dosage & 5 mg daily \\
\hline \multicolumn{5}{|c|}{ Melatonin Dosage for Neurological Issues } \\
\hline Oral & Starting Dosage & $10 \mathrm{mg}$ daily & Max Dosage & 80 mg daily \\
\hline Intravenous & Starting Dosage & $10 \mathrm{mg}$ daily & Max Dosage & $\begin{array}{l}50 \mathrm{mg} \text { daily } \\
\text { (titrate by } 10 \mathrm{mg} \text { until max dose is reached) }\end{array}$ \\
\hline Topical & Starting Dosage & $\mathrm{X}$ & Max Dosage & $\mathrm{X}$ \\
\hline
\end{tabular}

antioxidant and an efficient free radical scavenger, the combination of which makes melatonin very important for the body's ability to manage oxidative stress. As we discussed, managing oxidative stress is vital for the body's long-term health with high oxidative stress having a deleterious effect on the body, leading to cell death and conditions such as chronic inflammation, obesity, heart disease, and even neurological disease [138] [139] [140].

Perhaps, the most promising application of melatonin discussed in this report is as an anticancer agent. These anticancer properties have been widely studied in the literature; however, much remains to be discovered regarding the use of melatonin as a complementary anticancer agent. In vitro studies have yielded positive results, but clinical trials will be necessary to refine the use of melatonin for actual cancer patients. So far, researchers have been able to identify several relevant pathways for this anticancer effect. These mechanisms are related to antioxidant activity, modulation of MT1/MT2 receptors, apoptosis, pro-survival signaling, tumor metabolism, inhibition of angiogenesis, tissue invasion, and metastasis, and epigenetic alteration [16]. Overall, melatonin shows potential as an adjuvant for cancer therapy as it enhances the therapeutic effect of chemotherapy and radiation while mitigating some of the side effects [16]. Existing evidence from clinical use in humans is promising, showing that melatonin improves sleep and the quality of life in cancer patients [16]. With impressive efficacy from early trials and demonstrable safety in humans, melatonin seems to be 
a promising candidate for the prevention and treatment of cancer among its other potential therapeutic uses.

After reviewing the existing literature, the reviewers of this report on melatonin feel that good avenues of future research utilizing melatonin include more extensive epidemiological studies in consideration of the fact that the ones which exist now have provided inconsistent results, so far [16]. The inconsistent results may be due to sample size and composition, as well as the assessment methods used during the study. Larger studies in the future may yield more consistent results that fall in line with the experimental and clinical evidence collected in other trials. The effects of the different collection methods, such as between urine, plasma, and serum, should be elucidated and defined with the same sort of sample collection methods compared against one another. Sample collection time is another crucial factor since levels of melatonin fluctuate drastically depending on the time of day and the patient's sleep cycle. Future studies should account for this fluctuation explicitly by collecting samples during the same period for each patient and also ensuring that they are as close to the same point in their circadian rhythm as possible. For instance, a night shift worker will have a different melatonin pattern than a day worker even if samples are collected at the same time of day.

With regard to experimental and benchtop studies, we suggest that the regulatory nature of melatonin and the heterogeneous nature of cancer be taken into account. For example, during our research, we were able to find very few articles mentioning the process of autophagy with melatonin, which is a prominent mechanism of apoptosis. There are other molecular mechanisms that are also worthy of further scientific scrutiny, considering melatonin's protective effect with mitochondria and prevention of mitochondrial dysfunction. Finally, in the area of clinical trials, we recommend that melatonin be evaluated as an adjuvant for more anticancer drugs in order to obtain a broader sense of its potential applicability. Using melatonin in future clinical trials should provide valuable data on accurate dosage and define the long-term safety of melatonin administration.

\section{Conflicts of Interest}

The authors declare no conflicts of interest regarding the publication of this paper.

\section{References}

[1] Manchester, L.C., Poeggeler, B., Alvares, F.L., Ogden, G.B. and Reiter, R.J. (1995) Melatonin Immunoreactivity in the Photosynthetic Prokaryote Rhodospirillum rubrum: Implications for an Ancient Antioxidant System. Cellular and Molecular Biology Research, 41, 391-395.

[2] Suofu, Y., et al. (2017) Dual Role of Mitochondria in Producing Melatonin and Driving GPCR Signaling to Block Cytochrome c Release. Proceedings of the National Academy of Sciences, 114, E7997-E8006. https://doi.org/10.1073/pnas.1705768114

[3] Venegas, C., et al. (2012) Extrapineal Melatonin: Analysis of Its Subcellular Distri- 
bution and Daily Fluctuations. Journal of Pineal Research, 52, 217-227. https://doi.org/10.1111/j.1600-079X.2011.00931.x

[4] Auld, F., Maschauer, E.L., Morrison, I., Skene, D.J. and Riha, R.L. (2017) Evidence for the Efficacy of Melatonin in the Treatment of Primary Adult Sleep Disorders. Sleep Medicine Reviews, 34, 10-22. https://doi.org/10.1016/j.smrv.2016.06.005

[5] Karasek, M. (2004) Melatonin, Human Aging, and Age-Related Diseases. Experimental Gerontology, 39, 1723-1729. https://doi.org/10.1016/j.exger.2004.04.012

[6] Buscemi, N. (2004) Melatonin for treatment of sleep disorders. Agency for Healthcare Research and Quality.

[7] Matheson, E. and Hainer, B.L. (2017) Insomnia: Pharmacologic Therapy. American Family Physician, 96, 29-35.

[8] A and C Black (2008) British National Formulary.

[9] (2005) Melatonin. Alternative Medicine Review, 10, 326-336.

[10] Escames, G., et al. (2010) The Role of Mitochondria in Brain Aging and the Effects of Melatonin. Current Neuropharmacology, 8, 182-193.

https://doi.org/10.2174/157015910792246245

[11] Malhotra, S., Sawhney, G. and Pandhi, P. (2004) The Therapeutic Potential of Melatonin: A Review of the Science. Medscape General Medicine, 6, 46.

[12] Saumen Kumar, M. and Sourav, E. (2015) Gut Melatonin in Vertebrates: Chronobiology and Physiology. Frontiers in Endocrinology (Lausanne), 6, 112.

https://doi.org/10.3389/fendo.2015.00112

[13] Tosini, G., Ferguson, I. and Tsubota, K. (2016) Effects of Blue Light on the Circadian System and Eye Physiology. Molecular Vision, 22, 61-72.

[14] Scheer, F.A.J.L. and Czeisler, C.A. (2005) Melatonin, Sleep, and Circadian Rhythms. Sleep Medicine Reviews, 9, 5-9. https://doi.org/10.1016/j.smrv.2004.11.004

[15] Reiter, R.J., Paredes, S.D., Korkmaz, A., Jou, M.-J. and Tan, D.-X. (2008) Melatonin Combats Molecular Terrorism at the Mitochondrial Level. Interdisciplinary Toxicology, 1, 137-149. https://doi.org/10.2478/v10102-010-0030-2

[16] Li, Y., et al. (2017) Melatonin for the Prevention and Treatment of Cancer. Oncotarget, 8, 39896-39921. https://doi.org/10.18632/oncotarget.16379

[17] Xie, W., et al. (2017) Melatonin Potentiates “Inside-Out" Nano-Thermotherapy in Human Breast Cancer Cells: A Potential Cancer Target Multimodality Treatment Based on Melatonin-Loaded Nanocomposite Particles. International Journal of Nanomedicine, 12, 7351-7363. https://doi.org/10.2147/IJN.S148520

[18] Shiu, S.Y.W. (2007) Towards Rational and Evidence-Based Use of Melatonin in Prostate Cancer Prevention and Treatment. Journal of Pineal Research, 43, 1-9. https://doi.org/10.1111/j.1600-079X.2007.00451.x

[19] Wei, X., et al. (2018) Hyperbaric Oxygen Treatment Sensitizes Gastric Cancer Cells to Melatonin-Induced Apoptosis through Multiple Pathways. Journal of Cellular Biochemistry, 119, 6723-6731. https://doi.org/10.1002/jcb.26864

[20] Kvietkauskas, M., et al. (2020) The Role of Melatonin in Colorectal Cancer Treatment: A Comprehensive Review. Therapeutic Advances in Medical Oncology, 12, 1758835920931714. https://doi.org/10.1177/1758835920931714

[21] Yang, Y.-C., et al. (2019) Melatonin Reduces Lung Cancer Stemness through Inhibiting of PLC, ERK, p38, $\beta$-Catenin, and Twist Pathways. Environmental Toxicolo$g y, 34,203-209$. https://doi.org/10.1002/tox.22674

[22] Comai, S., Ochoa-Sanchez, R. and Gobbi, G. (2013) Sleep-Wake Characterization of 
Double MT1/MT2 Receptor Knockout Mice and Comparison with MT1 and MT2 Receptor Knockout Mice. Behavioural Brain Research, 243, 231-238. https://doi.org/10.1016/j.bbr.2013.01.008

[23] Carrillo-Vico, A., Lardone, P.J., Alvarez-Sánchez, N., Rodríguez-Rodríguez, A. and Guerrero, J.M. (2013) Melatonin: Buffering the Immune System. International Journal of Molecular Sciences, 14, 8638-8683. https://doi.org/10.3390/ijms14048638

[24] Foulkes, N.S., Assone-Corsi, P., Borjigin, J. and Snyder, S.H. (1997) Rhythmic Transcription: The Molecular Basis of Circadian Melatonin Synthesis. Trends in Neurosciences, 20, 487-492. https://doi.org/10.1016/S0166-2236(97)01109-0

[25] Kamal, M., et al. (2015) Convergence of Melatonin and Serotonin (5-HT) Signaling at MT2/5-HT2C Receptor Heteromers. The Journal of Biological Chemistry, 290, 11537-11546. https://doi.org/10.1074/jbc.M114.559542

[26] Christian De, B., et al. (2010) Agomelatine, the First Melatonergic Antidepressant: Discovery, Characterization and Development. Nature Reviews Drug Discovery, 9 , 628. https://doi.org/10.1038/nrd3140

[27] Stauch, B., et al. (2019) Structural Basis of Ligand Recognition at the Human MT1 Melatonin Receptor. Nature (London), 569, 284-288. https://doi.org/10.1038/s41586-019-1141-3

[28] Johansson, L.C., et al. (2019) XFEL Structures of the Human MT2 Melatonin Receptor Reveal the Basis of Subtype Selectivity. Nature (London), 569, 289-292. https://doi.org/10.1038/s41586-019-1144-0

[29] Murray, C.J. and Lopez, A.D. (1997) Alternative Projections of Mortality and Disability by Cause 1990-2020: Global Burden of Disease Study. The Lancet (London, England), 349, 1498-1504. https://doi.org/10.1016/S0140-6736(96)07492-2

[30] Golan, D., et al. (2013) The Influence of Vitamin D Supplementation on Melatonin Status in Patients with Multiple Sclerosis. Brain, Behavior, and Immunity, 32, 180-185. https://doi.org/10.1016/j.bbi.2013.04.010

[31] Williams, J.W., et al. (2000) A Systematic Review of Newer Pharmacotherapies for Depression in Adults: Evidence Report Summary. Annals of Internal Medicine, 132, 743-756. https://doi.org/10.7326/0003-4819-132-9-200005020-00011

[32] Anderson, I.M. and Tomenson, B.M. (1995) Treatment Discontinuation with Selective Serotonin Reuptake Inhibitors Compared with Tricyclic Antidepressants: A Meta-Analysis. BMJ: British Medical Journal, 310, 1433.

https://doi.org/10.1136/bmj.310.6992.1433

[33] Overstreet, H.D., Pucilowski, H.O., Retton, H.M.-C., Delagrange, H.P. and Guardiola-Lemaitre, H.B. (1998) Effects of Melatonin Receptor Ligands on Swim Test Immobility. NeuroReport, 9, 249-253.

https://doi.org/10.1097/00001756-199801260-00014

[34] Micale, V., Arezzi, A., Rampello, L. and Drago, F. (2006) Melatonin Affects the Immobility Time of Rats in the Forced Swim Test: The Role of Serotonin Neurotransmission. European Neuropsychopharmacology, 16, 538-545.

https://doi.org/10.1016/j.euroneuro.2006.01.005

[35] Pévet, P. (2016) Melatonin Receptors as Therapeutic Targets in the Suprachiasmatic Nucleus. Expert Opinion on Therapeutic Targets, 20, 1209-1218. https://doi.org/10.1080/14728222.2016.1179284

[36] Esposito, E. and Cuzzocrea, S. (2010) Antiinflammatory Activity of Melatonin in Central Nervous System. Current Neuropharmacology, 8, 228-242. https://doi.org/10.2174/157015910792246155 
[37] Mohan, N., Sadeghi, K., Reiter, R.J. and Meltz, M.L. (1995) The Neurohormone Melatonin Inhibits Cytokine, Mitogen and Ionizing Radiation Induced NF-kappa B. Biochemistry and Molecular Biology International, 37, 1063-1070.

[38] Calvo, J.R., González-Yanes, C. and Maldonado, M.D. (2013) The Role of Melatonin in the Cells of the Innate Immunity: A Review. Journal of Pineal Research, 55, 103-120. https://doi.org/10.1111/jpi.12075

[39] Carrillo-Vico, A., Guerrero, J., Lardone, P. and Reiter, R. (2005) A Review of the Multiple Actions of Melatonin on the Immune System. Endocrine, 27, 189-200. https://doi.org/10.1385/ENDO:27:2:189

[40] Molinero, P., Soutto, M., Benot, S., Hmadcha, A. and Guerrero, J.M. (2000) Melatonin Is Responsible for the Nocturnal Increase Observed in Serum and Thymus of Thymosin Alpha1 and Thymulin Concentrations: Observations in Rats and Humans. Journal of Neuroimmunology, 103, 180-188.

https://doi.org/10.1016/S0165-5728(99)00237-4

[41] Luchetti, F., et al. (2006) Melatonin Prevents Apoptosis Induced by UV-B Treatment in U937 Cell Line. Journal of Pineal Research, 40, 158-167.

https://doi.org/10.1111/j.1600-079X.2005.00293.x

[42] Pedrosa, A.M., et al. (2010) Melatonin Protects CD4+ T Cells from Activation-Induced Cell Death by Blocking NFAT-Mediated CD95 Ligand Upregulation. The Journal of Immunology, 184, 3487-3494. https://doi.org/10.4049/jimmunol.0902961

[43] Sánchez-Barceló, E.J., Mediavilla, M.D., Tan, D.X. and Reiter, R.J. (2010) Clinical Uses of Melatonin: Evaluation of Human Trials. Current Medicinal Chemistry, 17, 2070-2095. https://doi.org/10.2174/092986710791233689

[44] Cos, S. and Sánchez-Barceló, E.J. (1994) Differences between Pulsatile or Continuous Exposure to Melatonin on MCF-7 Human Breast Cancer Cell Proliferation. Cancer Letters, 85, 105-109. https://doi.org/10.1016/0304-3835(94)90245-3

[45] Lissoni, P., et al. (1995) Modulation of Cancer Endocrine Therapy by Melatonin: A Phase II Study of Tamoxifen plus Melatonin in Metastatic Breast Cancer Patients Progressing under Tamoxifen Alone. British Journal of Cancer, 71, 854. https://doi.org/10.1038/bjc.1995.164

[46] Neri, B., et al. (1994) Modulation of Human Lymphoblastoid Interferon Activity by Melatonin in Metastatic Renal Cell Carcinoma. A Phase II Study. Cancer, 73, 3015-3019. https://doi.org/10.1002/1097-0142(19940615)73:12<3015::AID-CNCR2820731220> 3.0.CO;2-N

[47] Lissoni, P., et al. (1992) Randomized Study with the Pineal Hormone Melatonin versus Supportive Care Alone in Advanced Nonsmall Cell Lung Cancer Resistant to a First-Line Chemotherapy Containing Cisplatin. Oncology, 49, 336-339. https://doi.org/10.1159/000227068

[48] Aldeghi, R., et al. (1994) Low-Dose Interleukin-2 Subcutaneous Immunotherapy in Association with the Pineal Hormone Melatonin as a First-Line Therapy in Locally Advanced or Metastatic Hepatocellular-Carcinoma. European Journal of Cancer, 30, 167-170. https://doi.org/10.1016/0959-8049(94)90080-9

[49] Lissoni, P., et al. (1994) A Randomized Study with the Pineal Hormone Melatonin versus Supportive Care Alone in Patients with Brain Metastases Due to Solid Neoplasms. Cancer, 73, 699-701.

https://doi.org/10.1002/1097-0142(19940201)73:3<699::AID-CNCR2820730332>3.0 .CO;2-L

[50] González-González, A., et al. (2020) Usefulness of Melatonin as Complementary to Chemotherapeutic Agents at Different Stages of the Angiogenic Process. Scientific 
Reports, 10, Article No. 4790. https://doi.org/10.1038/s41598-020-61622-x

[51] Russo, I. and Russo, J. (1998) Role of Hormones in Mammary Cancer Initiation and Progression. Journal of Mammary Gland Biology and Neoplasia, 3, 49-61. https://doi.org/10.1023/A:1018770218022

[52] Cohen, M., Lippman, M. and Chabner, B. (1978) Role of Pineal Gland in Aetiology and Treatment of Breast Cancer. The Lancet (London, England), 2, 814-816. https://doi.org/10.1016/S0140-6736(78)92591-6

[53] Blask, D., et al. (1991) Pineal Melatonin Inhibition of Tumor Promotion in the N-nitroso-N-methylurea Model of Mammary Carcinogenesis: Potential Involvement of Antiestrogenic Mechanisms in Vivo. Journal of Cancer Research and Clinical Oncology, 117, 526-532. https://doi.org/10.1007/BF01613283

[54] American Cancer Society (2020) Cancer Facts and Figures. https://www.cancer.org/content/dam/cancer-org/research/cancer-facts-and-statistic s/annual-cancer-facts-and-figures/2020/cancer-facts-and-figures-2020.pdf

[55] Pariente, R., Bejarano, I., Rodríguez, A.B., Pariente, J.A. and Espino, J. (2018) Melatonin Increases the Effect of 5-Fluorouracil-Based Chemotherapy in Human Colorectal Adenocarcinoma Cells in Vitro. Molecular and Cellular Biochemistry, 440, 43-51. https://doi.org/10.1007/s11010-017-3154-2

[56] Conant, K. and Gottschall, P. (2005) Matrix Metalloproteinases in the Central Nervous System. Imperial College Press.

[57] Pal, S., Ganguly, K.K. and Chatterjee, A. (2013) Extracellular Matrix Protein Fibronectin Induces Matrix Metalloproteinases in Human Prostate Adenocarcinoma Cells PC-3. Cell Communication and Adhesion, 20, 105-114. https://doi.org/10.3109/15419061.2013.833193

[58] Fridman, R., Toth, M., Chvyrkova, I., Meroueh, S. and Mobashery, S. (2003) Cell Surface Association of Matrix Metalloproteinase-9 (Gelatinase B). Cancer and $\mathrm{Me}$ tastasis Reviews, 22, 153-166. https://doi.org/10.1023/A:1023091214123

[59] Ramos-Desimone, N., et al. (1999) Activation of Matrix Metalloproteinase-9 (MMP-9) via a Converging Plasmin/Stromelysin-1 Cascade Enhances Tumor Cell Invasion. Journal of Biological Chemistry, 274, 13066-13076. https://doi.org/10.1074/jbc.274.19.13066

[60] Vu, T.H., et al. (1998) MMP-9/Gelatinase B Is a Key Regulator of Growth Plate Angiogenesis and Apoptosis of Hypertrophic Chondrocytes. Cell, 93, 411-422. https://doi.org/10.1016/S0092-8674(00)81169-1

[61] Johnson, M.C., Sung, E.H.-J., Lessner, S.S., Fini, S.M. and Galis, S.Z. (2004) Matrix Metalloproteinase-9 Is Required for Adequate Angiogenic Revascularization of Ischemic Tissues: Potential Role in Capillary Branching. Circulation Research: Journal of the American Heart Association, 94, 262-268. https://doi.org/10.1161/01.RES.0000111527.42357.62

[62] Larsen, P.H., Wells, J.E., Stallcup, W.B., Opdenakker, G. and Yong, V.W. (2003) Matrix Metalloproteinase-9 Facilitates Remyelination in Part by Processing the Inhibitory NG2 Proteoglycan. The Journal of Neuroscience: The Official Journal of the Society for Neuroscience, 23, 11127-11135. https://doi.org/10.1523/JNEUROSCI.23-35-11127.2003

[63] Ram, M., Sherer, Y. and Shoenfeld, Y. (2006) Matrix Metalloproteinase-9 and Autoimmune Diseases. Journal of Clinical Immunology, 26, 299-307. https://doi.org/10.1007/s10875-006-9022-6

[64] Rohde, L.E., et al. (1999) Matrix Metalloproteinase Inhibition Attenuates Early Left 
Ventricular Enlargement after Experimental Myocardial Infarction in Mice. Circulation, 99, 3063-3070. https://doi.org/10.1161/01.CIR.99.23.3063

[65] Sellner, J. and Leib, S.L. (2006) In Bacterial Meningitis Cortical Brain Damage Is Associated with Changes in Parenchymal MMP-9/TIMP-1 Ratio and Increased Collagen Type IV Degradation. Neurobiology of Disease, 21, 647-656. https://doi.org/10.1016/j.nbd.2005.09.007

[66] Starckx, S., Van Den Steen, P.E., Verbeek, R., van Noort, J.M. and Opdenakker, G. (2003) A Novel Rationale for Inhibition of Gelatinase B in Multiple Sclerosis: MMP-9 Destroys $\alpha \mathrm{B}$-Crystallin and Generates a Promiscuous T Cell Epitope. Journal of Neuroimmunology, 141, 47-57.

https://doi.org/10.1016/S0165-5728(03)00217-0

[67] Vandooren, J., Van den Steen, P.E. and Opdenakker, G. (2013) Biochemistry and Molecular Biology of Gelatinase B or Matrix Metalloproteinase-9 (MMP-9): The Next Decade. Critical Reviews in Biochemistry and Molecular Biology, 48, 222-272. https://doi.org/10.3109/10409238.2013.770819

[68] Egeblad, M. and Werb, Z. (2002) New Functions for the Matrix Metalloproteinases in Cancer Progression. Nature Reviews Cancer, 2, 161-174.

https://doi.org/10.1038/nrc745

[69] Iurlaro, et al. (1999) Angiogenesis Extent and Expression of Matrix Metalloproteinase-2 and -9 Correlate with Upgrading and Myometrial Invasion in Endometrial Carcinoma. European Journal of Clinical Investigation, 29, 793-801. https://doi.org/10.1046/j.1365-2362.1999.00532.x

[70] Bergers, G., et al. (2000) Matrix Metalloproteinase-9 Triggers the Angiogenic Switch during Carcinogenesis. Nature Cell Biology, 2, 737-744.

https://doi.org/10.1038/35036374

[71] Acuff, H.B., Carter, K.J., Fingleton, B., Gorden, D.L. and Matrisian, L.M. (2006) Matrix Metalloproteinase-9 from Bone Marrow-Derived Cells Contributes to Survival But Not Growth of Tumor Cells in the Lung Microenvironment. Cancer Research, 66, 259-266. https://doi.org/10.1158/0008-5472.CAN-05-2502

[72] Zucker, S., Lysik, R.M., Zarrabi, M.H. and Moll, U. (1993) M(r) 92,000 Type IV Collagenase Is Increased in Plasma of Patients with Colon Cancer and Breast Cancer. Cancer Research, 53, 140-146.

[73] Tochowicz, A., et al. (2007) Crystal Structures of MMP-9 Complexes with Five Inhibitors: Contribution of the Flexible Arg424 Side-Chain to Selectivity. Journal of Molecular Biology, 371, 989-1006. https://doi.org/10.1016/j.jmb.2007.05.068

[74] Ganguly, K., Kundu, P., Banerjee, A., Reiter, R.J. and Swarnakar, S. (2006) Hydrogen Peroxide-Mediated Downregulation of Matrix Metalloprotease-2 in Indomethacin-Induced Acute Gastric Ulceration Is Blocked by Melatonin and Other Antioxidants. Free Radical Biology and Medicine, 41, 911-925. https://doi.org/10.1016/j.freeradbiomed.2006.04.022

[75] Mishra, A., Paul, S. and Swarnakar, S. (2011) Downregulation of Matrix Metalloproteinase- 9 by Melatonin during Prevention of Alcohol-Induced Liver Injury in Mice. Biochimie, 93, 854-866. https://doi.org/10.1016/j.biochi.2011.02.007

[76] Motilva, V., García-Mauriño, S., Talero, E. and Illanes, M. (2011) New Paradigms in Chronic Intestinal Inflammation and Colon Cancer: Role of Melatonin. Journal of Pineal Research, 51, 44-60. https://doi.org/10.1111/j.1600-079X.2011.00915.x

[77] Galano, A., Tan, D.X. and Reiter, R.J. (2011) Melatonin as a Natural Ally against Oxidative Stress: A Physicochemical Examination. Journal of Pineal Research, 51, 1-16. https://doi.org/10.1111/j.1600-079X.2011.00916.x 
[78] Poeggeler, B., et al. (1994) Melatonin-A Highly Potent Endogenous Radical Scavenger and Electron Donor: New Aspects of the Oxidation Chemistry of This Indole Accessed in Vitro. Annals of the New York Academy of Sciences, 738, 419-420. https://doi.org/10.1111/j.1749-6632.1994.tb21831.x

[79] Tan, D.-X., et al. (2002) Chemical and Physical Properties and Potential Mechanisms: Melatonin as a Broad Spectrum Antioxidant and Free Radical Scavenger. Current Topics in Medicinal Chemistry, 2, 181-197. https://doi.org/10.2174/1568026023394443

[80] Rudra, D.S., Pal, U., Maiti, N.C., Reiter, R.J. and Swarnakar, S. (2013) Melatonin Inhibits Matrix Metalloproteinase-9 Activity by Binding to Its Active Site. Journal of Pineal Research, 54, 398-405. https://doi.org/10.1111/jpi.12034

[81] Cutando, A., Lopez-Valverde, A., Arias-Santiago, S., De Vicente, J. and De Diego, R.G. (2012) Role of Melatonin in Cancer Treatment. AntiCancer Research, 32, 2747-2753.

[82] Scheiermann, C., Kunisaki, Y. and Frenette, P.S. (2013) Circadian Control of the Immune System. Nature Reviews Immunology, 13, 190-198.

https://doi.org/10.1038/nri3386

[83] Christopher, J.M., Taylor, E.P., Kun, H. and Frank, A.J.L.S. (2016) Circadian Misalignment Increases Cardiovascular Disease Risk Factors in Humans. Proceedings of the National Academy of Sciences, 113, E1402. https://doi.org/10.1073/pnas.1516953113

[84] Jim, H., Tyrer, J., Lin, H., Han, G., Qu, X., Goode, E., Chen, Z., Tsai, Y., Cunningham, J., Iversen, E., Ramus, S., Berchuck, A., Schildkraut, J., Monteiro, A., Gayther, S., Narod, S., Sellers, T., Pharoah, P. and Phelan, C. (2013) Abstract 4850: Variation in Circadian Rhythm Genes Influence Epithelial Ovarian Cancer Risk and Invasiveness. Cancer Research (Chicago, Ill.), 73, 4850. https://doi.org/10.1158/1538-7445.AM2013-4850

[85] Blask, D.E., et al. (2005) Melatonin-Depleted Blood from Premenopausal Women Exposed to Light at Night Stimulates Growth of Human Breast Cancer Xenografts in Nude Rats. Cancer Research, 65, 11174-11184. https://doi.org/10.1158/0008-5472.CAN-05-1945

[86] Lardone, P.J., Carrillo-Vico, A., Molinero, P., Rubio, A. and Guerrero, J.M. (2009) A Novel Interplay between Membrane and Nuclear Melatonin Receptors in Human Lymphocytes: Significance in IL-2 Production. Cellular and Molecular Life Sciences, 66, 516-525. https://doi.org/10.1007/s00018-008-8601-5

[87] Koebel, C.M., et al. (2007) Adaptive Immunity Maintains Occult Cancer in an Equilibrium State. Nature, 450, 903-907. https://doi.org/10.1038/nature06309

[88] Knutson, K.L., Disis, M.L. and Salazar, L.G. (2007) CD4 Regulatory T Cells in Human Cancer Pathogenesis. Cancer Immunology, Immunotherapy, 56, 271-285.

https://doi.org/10.1007/s00262-006-0194-y

[89] Liu, H., et al. (2011) Role of CD4+ CD25+ Regulatory T Cells in Melatonin-Mediated Inhibition of Murine Gastric Cancer Cell Growth in Vivo and in Vitro. The Anatomical Record (Hoboken), 294, 781-788. https://doi.org/10.1002/ar.21361

[90] Vigoré, L., et al. (2010) Psychoneuroendocrine Modulation of Regulatory T Lymphocyte System: In Vivo and in Vitro Effects of the Pineal Immunomodulating Hormone Melatonin. In Vivo, 24, 787-789.

[91] Kawaguchi, K., et al. (2019) Alteration of Specific Cytokine Expression Patterns in Patients with Breast Cancer. Scientific Reports, 9, Article No. 2924. 
https://doi.org/10.1038/s41598-019-39476-9

[92] Marotta, L.L.C. and Polyak, K. (2011) Unraveling the Complexity of Basal-Like Breast Cancer. Oncotarget, 2, 588-589. https://doi.org/10.18632/oncotarget.314

[93] Leek, R.D. and Harris, A.L. (2002) Tumor-Associated Macrophages in Breast Cancer. Journal of Mammary Gland Biology and Neoplasia, 7, 177-189. https://doi.org/10.1023/A:1020304003704

[94] Lacoste, B., et al. (2015) Anatomical and Cellular Localization of Melatonin MT1 and MT2 Receptors in the Adult Rat Brain. Journal of Pineal Research, 58, 397-417. https://doi.org/10.1111/jpi.12224

[95] Reiter, R.J., et al. (2007) Medical Implications of Melatonin: Receptor-Mediated and Receptor-Independent Actions. Advances in Medical Sciences, 52, 11-28.

[96] Slominski, R.M., Reiter, R.J., Schlabritz-Loutsevitch, N., Ostrom, R.S. and Slominski, A.T. (2012) Melatonin Membrane Receptors in Peripheral Tissues: Distribution and Functions. Molecular and Cellular Endocrinology, 351, 152-166. https://doi.org/10.1016/j.mce.2012.01.004

[97] He, B., et al. (2016) The Nuclear Melatonin Receptor ROR $\alpha$ Is a Novel Endogenous Defender against Myocardial Ischemia/Reperfusion Injury. Journal of Pineal Research, 60, 313-326. https://doi.org/10.1111/jpi.12312

[98] Lardone, P.J., et al. (2011) Melatonin Synthesized by T Lymphocytes as a Ligand of the Retinoic Acid-Related Orphan Receptor. Journal of Pineal Research, 51, 454-462. https://doi.org/10.1111/j.1600-079X.2011.00909.x

[99] Becker-André, M., et al. (1994) Pineal Gland Hormone Melatonin Binds and Activates an Orphan of the Nuclear Receptor Superfamily. The Journal of Biological Chemistry, 269, 28531-28534.

[100] Pozo, D., et al. (1997) Expression of the Mella-Melatonin Receptor mRNA in T and B Subsets of Lymphocytes from Rat Thymus and Spleen. FASEB Journal, 11, 466-473. https://doi.org/10.1096/fasebj.11.6.9194527

[101] Gonzalez-Haba, M.G., Garcia-Mauriño, S., Calvo, J.R., Goberna, R. and Guerrero, J.M. (1995) High-Affinity Binding of Melatonin by Human Circulating T Lymphocytes (CD4+). FASEB Journal, 9, 1331-1335. https://doi.org/10.1096/fasebj.9.13.7557023

[102] Ren, W., et al. (2017) Melatonin Signaling in T Cells: Functions and Applications. Journal of Pineal Research, 62, e12394. https://doi.org/10.1111/jpi.12394

[103] Dempsey, L. (2015) Melatonin Zaps TH17. Nature Immunology, 16, 1113. https://doi.org/10.1038/ni.3300

[104] Knochelmann, H.M., et al. (2018) When Worlds Collide: Th17 and Treg Cells in Cancer and Autoimmunity. Cellular and Molecular Immunology, 15, 458-469. https://doi.org/10.1038/s41423-018-0004-4

[105] Luo, J., et al. (2020) Effect of Melatonin on T/B Cell Activation and Immune Regulation in Pinealectomy Mice. Life Sciences, 242, Article ID: 117191. https://doi.org/10.1016/j.lfs.2019.117191

[106] Mediavilla, M.D., Sanchez-Barcelo, E.J., Tan, D.X., Manchester, L. and Reiter, R.J. (2010) Basic Mechanisms Involved in the Anti-Cancer Effects of Melatonin. Current Medicinal Chemistry, 17, 4462-4481. https://doi.org/10.2174/092986710794183015

[107] Casado-Zapico, S., et al. (2010) Synergistic Antitumor Effect of Melatonin with Several Chemotherapeutic Drugs on Human Ewing Sarcoma Cancer Cells: Potentiation of the Extrinsic Apoptotic Pathway. Journal of Pineal Research, 48, 72-80. 
https://doi.org/10.1111/j.1600-079X.2009.00727.x

[108] Reiter, R.J., Tan, D.X., Sainz, R.M., Mayo, J.C. and Lopez-Burillo, S. (2002) Melatonin: Reducing the Toxicity and Increasing the Efficacy of Drugs. Journal of Pharmacy and Pharmacology, 54, 1299-1321. https://doi.org/10.1211/002235702760345374

[109] Benítez-King, G., Soto-Vega, E. and Ramírez-Rodriguez, G. (2009) Melatonin Modulates Microfilament Phenotypes in Epithelial Cells: Implications for Adhesion and Inhibition of Cancer Cell Migration. Histology and Histopathology, 24, 789-799.

[110] Fan, L., Sun, G., Ma, T., Zhong, F. and Wei, W. (2013) Melatonin Overcomes Apoptosis Resistance in Human Hepatocellular Carcinoma by Targeting Survivin and XIAP. Journal of Pineal Research, 55, 174-183.

https://doi.org/10.1111/jpi.12060

[111] Cho, C. and Yu, J. (2012) From Inflammation to Cancer: Advances in Diagnosis and Therapy for Gastrointestinal and Hepatological Diseases. In From Inflammation to Cancer. World Scientific Publishing Co. Pte. Ltd. https://doi.org/10.1142/8117

[112] Rauch, D., et al. (2009) Imaging Spontaneous Tumorigenesis: Inflammation Precedes Development of Peripheral NK Tumors. Blood, 113, 1493-1500. https://doi.org/10.1182/blood-2008-07-166462

[113] Zhang, X., et al. (2015) Inflammation-Induced S100A8 Activates Id3 and Promotes Colorectal Tumorigenesis. International Journal of Cancer, 137, 2803-2814. https://doi.org/10.1002/ijc.29671

[114] Urata, Y., et al. (1999) Melatonin Induces $\gamma$-Glutamylcysteine Synthetase Mediated by Activator Protein-1 in Human Vascular Endothelial Cells. Free Radical Biology and Medicine, 27, 838-847. https://doi.org/10.1016/S0891-5849(99)00131-8

[115] Hey-Mogensen, M., et al. (2010) Effect of Physical Training on Mitochondrial Respiration and Reactive Oxygen Species Release in Skeletal Muscle in Patients with Obesity and Type 2 Diabetes. Diabetologia, 53, 1976. https://doi.org/10.1007/s00125-010-1813-X

[116] Tan, D.-X., et al. (2000) Melatonin Directly Scavenges Hydrogen Peroxide: A Potentially New Metabolic Pathway of Melatonin Biotransformation. Free Radical Biology and Medicine, 29, 1177-1185. https://doi.org/10.1016/S0891-5849(00)00435-4

[117] Aydogan, S., Yerer, M.B. and Goktas, A. (2006) Melatonin and Nitric Oxide. Journal of Endocrinological Investigation, 29, 281-287. https://doi.org/10.1007/BF03345555

[118] Munn, E.A. (1974) The Structure of Mitochondria. Elsevier, Amsterdam. https://doi.org/10.1016/B978-0-12-510150-9.50008-0

[119] Acuña-Castroviejo, D., Escames, G., León, J., Carazo, A. and Khaldy, H. (2003) Mitochondrial Regulation by Melatonin and Its Metabolites. Advances in Experimental Medicine and Biology, 527, 549. https://doi.org/10.1007/978-1-4615-0135-0_63

[120] Saravanan, K.S., Sindhu, K.M. and Mohanakumar, K.P. (2007) Melatonin Protects against Rotenone-Induced Oxidative Stress in a Hemiparkinsonian Rat Model. Journal of Pineal Research, 42, 247-253. https://doi.org/10.1111/j.1600-079X.2006.00412.x

[121] Stvolinsky, S., Fedorova, N. and Boldyrev, A. (2007) MPTP-Induced Parkinsonian Syndrome in Senescence Accelerated Mice (SAM). Parkinsonism and Related Disorders, 13, S128-S128. https://doi.org/10.1016/S1353-8020(08)70723-5

[122] Acuña-Castroviejo, D., Coto-Montes, A., Monti, M.G., Ortiz, G.G. and Reiter, R.J. 
(1996) Melatonin Is Protective against MPTP-Induced Striatal and Hippocampal Lesions. Life Sciences, 60, PL23-PL29. https://doi.org/10.1016/S0024-3205(96)00606-6

[123] Túnez, I., Montilla, P., Del Carmen Muñoz, M., Feijóo, M. and Salcedo, M. (2004) Protective Effect of Melatonin on 3-Nitropropionic Acid-Induced Oxidative Stress in Synaptosomes in an Animal Model of Huntington's Disease. Journal of Pineal Research, 37, 252-256. https://doi.org/10.1111/j.1600-079X.2004.00163.x

[124] Yamamoto, H.-A. and Mohanan, P.V. (2002) Melatonin Attenuates Brain Mitochondria DNA Damage Induced by Potassium Cyanide in Vivo and in Vitro. Toxicology, 179, 29-36. https://doi.org/10.1016/S0300-483X(02)00244-5

[125] Yamamoto, H.-A. and Tang, H.-W. (1996) Preventive Effect of Melatonin against Cyanide-Induced Seizures and Lipid Peroxidation in Mice. Neuroscience Letters, 207, 89-92. https://doi.org/10.1016/0304-3940(96)12493-9

[126] Floyd, R.A. and Hensley, K. (2002) Oxidative Stress in Brain Aging: Implications for Therapeutics of Neurodegenerative Diseases. Neurobiology of Aging, 23, 795-807. https://doi.org/10.1016/S0197-4580(02)00019-2

[127] Hill, J.M. and Switzer, R.C. (1984) The Regional Distribution and Cellular Localization of Iron in the Rat Brain. Neuroscience, 11, 595-603.

https://doi.org/10.1016/0306-4522(84)90046-0

[128] Sanchez-Moreno, C., Dorfman, S., Lichtenstein, A. and Martin, A. (2004) Dietary Fat Type Affects Vitamins C and E and Biomarkers of Oxidative Status in Peripheral and Brain Tissues of Golden Syrian Hamsters. The Journal of Nutrition, 134, 655-660. https://doi.org/10.1093/jn/134.3.655

[129] Antolín, I., et al. (1996) Neurohormone Melatonin Prevents Cell Damage: Effect on Gene Expression for Antioxidant Enzymes. FASEB Journal, 10, 882-890. https://doi.org/10.1096/fasebj.10.8.8666165

[130] Rosenbluth, J. (1980) Central Myelin in the Mouse Mutant Shiverer. Journal of Comparative Neurology, 194, 639-648. https://doi.org/10.1002/cne.901940310

[131] Hopp, D.C. and Shurtleff, D. (2019) Melatonin: What You Need to Know. https://www.nccih.nih.gov/health/melatonin-what-you-need-to-know

[132] Mayo Clinic Staff (2018) Melatonin. https://www.mayoclinic.org/drugs-supplements-melatonin/art-20363071

[133] (2009) Agomelatine: New Drug. Adverse Effects and No Proven Efficacy. Prescrire International, 18, 241-245.

[134] Costello, R., et al. (2014) The Effectiveness of Melatonin for Promoting Healthy Sleep: A Rapid Evidence Assessment of the Literature. Nutrition Journal, 13, 106. https://doi.org/10.1186/1475-2891-13-106

[135] Hardeland, R., et al. (2008) Melatonergic Drugs in Clinical Practice. Arzneimittel-Forschung, 58, 1-10. https://doi.org/10.1055/s-0031-1296459

[136] Emet, M., et al. (2016) A Review of Melatonin, Its Receptors and Drugs/Bir Melatonin Derlemesi, Reseptörleri ve Ilaçlari. Eurasian Journal of Medicine, 48, 135-141. https://doi.org/10.5152/eurasianjmed.2015.0267

[137] Hardeland, R. (2012) Melatonin in Aging and Disease-Multiple Consequences of Reduced Secretion, Options and Limits of Treatment. Aging and Disease, 3, 194-225.

[138] Lin, T.-H., Lai, W.-T. and Sheu, S.-H. (2011) Relationship between Adipokines, Inflammation, Oxidative Stress, Insulin Resistance and Family History of Hypertension in Young-Onset Hypertensives. Journal of the American College of Cardiology, 57, E527. https://doi.org/10.1016/S0735-1097(11)60527-5 
[139] Paik, J.K., et al. (2012) Circulating and PBMC Lp-PLA 2 Associate Differently with Oxidative Stress and Subclinical Inflammation in Nonobese Women (Menopausal Status) (Lp-PLA 2 Activity, Inflammation and Oxidative Stress). PLoS ONE, 7, e29675. https://doi.org/10.1371/journal.pone.0029675

[140] Finelli, M. and Oliver, P. (2017) TLDc Proteins: New Players in the Oxidative Stress Response and Neurological Disease. Mammalian Genome, 28, 395-406.

https://doi.org/10.1007/s00335-017-9706-7 